\title{
A STATISTICAL APPROACH TO THE ESTIMATION OF BICYCLE LEVEL OF SERVICE MODELS FOR THE CICLORUTA IN BOGOTA, COLOMBIA
}

\author{
INAH OKON ${ }^{1}$, MARK J. G. BRUSSEL ${ }^{2}$, FRANS H. M. VAN DEN BOSCH ${ }^{2}$, CARLOS A. MORENO \\ \& MARTIN F. A. M. VAN MAARSEVEEN ${ }^{2}$ \\ ${ }^{1}$ Department of Geography \& Environmental Science, University of Calabar, Nigeria \\ ${ }^{2}$ Urban Planning \& Management, Faculty of GeoInformation Science and \\ Earth Observation, University of Twente, The Netherlands \\ ${ }^{3}$ Faculty of Architecture, Universidad Piloto de Colombia, Colombia
}

\begin{abstract}
Understanding the perception of level of service (LOS) of cyclists can be useful in developing a planning strategy for promoting intra-city bicycle commuting. In Bogota, the enormous resource investment in the Cicloruta system requires a regular infrastructure audit to ascertain its level of performance. Videos of 16 segments and 8 intersections were carefully collected and showed to participants who rated their level of satisfaction using a 6-point scale (A-F - 'highly satisfied' to 'highly dissatisfied'), equivalent to 1360 segments and 680 intersections (2040 total ratings). The perception data was augmented with geometrical, physical and operational characteristics of traffic in the area. Most participants fall within ages of $18-35$ in both male $(88.9 \%)$ and female $(77.4 \%)$ while bicycle ridership also revealed more riders in male $(75.9 \%)$ than in female $(58.1 \%)$. The study showed that $69.4 \%$ of participants ride bicycles in the city while $30.6 \%$ do not. Ordered probability models were used to estimate random parameters of cyclists LOS perception to account for unobserved heterogeneity for all respondents. Bicycle level of service (BLOS) was strongly influenced by side path separation $(\beta=0.605, p<0.05)$; vehicle speed $(\beta=0.717, p<0.05)$; motorised traffic volume $(\beta=-0.381, p<0.05)$; and conflicts with pedestrians $(\beta=1.173, p<0.05)$. Furthermore, other factors were also found to have high probabilities to influence LOS including bicycle lane width, wide outside lane, pavement conditions, trees and benches, daylight, gender and the experience of the cyclist. A model for intersection LOS was estimated, the results of which results reveal that the volume of cyclists $(\beta=1.116, p<0.05)$, conflicts with pedestrians/other cyclists $(\beta=1.048, p<0.05)$ and total intersection legs $(\beta=-0.365, p<0.05)$ are factors with a high influence on cyclist's LOS. The variety of factors affecting bicyclists reveal the nature and character of urban transportation in Bogota and suggest a range of important recommendations such as education and public enlightenment of cyclists and motorists, in further planning and management of the Cicloruta.
\end{abstract}

Keywords: bicyclist, segment bicycle level of service, intersection bicycle level of service, ordered probit models, Cicloruta.

\section{INTRODUCTION}

The promotion of bicycling has become a global strategy in sustainable urban transportation planning. Among others, cycling has the potential to reduce intra-urban problems that result from the dominance of motorised urban transport [1]. These problems include, traffic congestion, noise, accidents or outright death, urban air quality degradation and high energy consumption. Until recently, the driving force of this trend according to Asadi-Shekari et al. [2] has been speed rather than energy efficiency. Therefore, the task of providing accessibility and mobility to all travellers in the city in a sustainable manner remains complex due to their conflicting modal choices, different income classes and preferences, safety concerns and the lack of supporting infrastructure for some of these modes. The inability to strike a balance between modes that reduce pollution and those that reduce speed or accidents has been of concern to transport planners. Many cities have been implementing cycling promotion 
programmes worldwide, however with varying degrees of success [3]-[5]. This variation is due to differences in socio-economic, cultural and technological development, but also a variety of other characteristics like weather and topographic conditions, quality of infrastructure and traffic safety. As a result, users across different countries and cities perceive different satisfaction levels. This is perhaps why it is no possible to have generally acceptable statistically calibrated models at global or national scale for assessment of the satisfaction of bicycle commuting.

However, at specific city levels, several attempts have been made to develop measures and standards for assessing bicycle commuting satisfaction. For instance, Dixon [6] used the segment as the unit of analysis to develop a bicycle and pedestrian level of service (PLOS) performance measure in Gainesville, Florida as input into a congestion management plan. From the user's perspective, Kang and Lee [4] similarly developed a bicycle level of service (BLOS) model for South Korea using 'facility, operation, intersection and safety characteristics'. On the other hand, Providelo and da Penha Sanches [1] used successive interval analysis to develop a level of service (LOS) for a medium-sized Brazilian city that described the level of satisfaction from bicycle infrastructure. And in their 'real-time human perceptions' study of American cities towards a bicycle level of service, Landis et al. [7] mathematically expressed basic traffic conditions for road segments that influence bicyclists' level of service perception. Basic variables of their equation include per-lane motor vehicle traffic volume, speed of motor vehicles, traffic mix, potential cross-traffic generation, pavement surface condition and width for bicycling. Unlike earlier LOS studies, our study is among the few that uses both qualitative (participants' ratings) and quantitative (measurement and observation) data; and a combination of segment and intersection data to estimate BLOS models.

The question of how to increase bikeability has occupied the minds of researchers and policy makers for decades. This is not without consideration of attendant huge capital investments on infrastructure and different perception levels of satisfaction. For instance, from 1999 to 2002, the Bogota city government has invested US\$1.7 billion on infrastructure related projects, where US\$180 million was spent alone on bikeways [8]. The main goal was to integrate bicycling as an alternative intra-urban transport system thereby reducing congestion, accidents and pollution levels, thus promoting wellbeing in Bogota. As the capital of Colombia and home to some seven million inhabitants, its high population and volume of socio-economic activities have the attendant consequences of traffic-related impacts including, traffic congestion, noise, accidents, loss of man hours; and pollution at all levels. These slow down the socio-economic pace of the city. These realisations have led to the development of the bus rapid transit (BRT) otherwise referred to as 'TransMilenio' (55 $\mathrm{km}$ ) and the extensive network of dedicated bicycle paths called 'CicloRuta' measuring about $300 \mathrm{~km}$. These multi-million-dollar projects according to Skinner [9] have brought Bogota into the limelight of urban transit literature, and are expected to double and become a world class infrastructure in 30 years. Notwithstanding these investments and the wide acclaim that they have generated worldwide, the Cicloruta system has not been able to live up to its promise to make cycling an everyday choice for Bogotanos. At the moment, cycling in Bogota has a modal share of about $3.3 \%$ on a total of about 10 million daily trips [10]. The system therefore is heavily underutilised and the question of how to increase bikeability is an important one to answer in this context. This study is aimed develop a methodology for the estimation of bicycle level of service by using residents' perception of satisfaction and other road geometry, physical and operational measurements. 


\section{LITERATURE REVIEW}

The need for research on the level of cyclists' satisfaction is based on the consensus that level of bicycle use is strongly related to available infrastructure and safety issues. The advantages of bicycle transportation such as pollution-free [11], [12] and good health [13] notwithstanding, it presents safety especially if infrastructure for it is not well planned [14]. This lack of suitable facilities reduces the use of bicycle transportation. Some studies observed limited cycling paths in transport networks which underscores the fact that cycling is not a transport system that is for specific streets [15]. Several researches have proposed different kinds of facilities to encourage the use of the bicycle for urban transport commuting [16]-[18]. Thus, a consensus exists on factors such as availability, quality and type of cycling facilities as prominent among others that influence cycling. For example, bicycle paths were observed to attract more cyclists by Tilahun et al. [19].

From the foregoing therefore, a different terminology and methodologies have emerged for investigating bicyclists' satisfaction from the use of specific facilities. For example, Davis [20] developed the bicycle safety index rating (BSIR) as one of the first attempts to evaluate the comfort and safety level of bicyclists using mathematical models. With no additional changes made in the BSIR model except for the modification of some values for location and pavement indicators, the Broward County in 1991 used it as roadway condition index (RCI) [21]. Profound amongst critics of this model was Epperson [22] for the non-inclusion of information on signalised intersections, non-validation of the rating system against bicyclist perception or real time accident data. In an apparent attempt to revise BSIR, Davis [23] postulated the bicycle suitability rating (BSR) where he examined roadway segments as a component of bicycle suitability rating, having dropped the intersection evaluation index. The concept of bicycle stress level (BSL) was used to relate bicyclists' perception of satisfaction on specific roadway geometry and traffic conditions [24]. This was one of the first attempts to gather responses from independent participants other than team members of a project.

Furthermore, Harkey et al. [25] proposed the bicycle compatibility index (BCI) to evaluate the 'cycling-friendly environment' by estimating the quality of streets from rated grade levels of 'A' for highly compatible and ' $\mathrm{F}$ ' for highly incompatible for cycling. The actual model development was done by Hallett et al. [26], who were criticised for the exclusion of some important indicators like, 'lighting, bike box, parking, signage and markings'. The interaction hazard score (IHS) was developed to evaluate bicycle suitability in some urban areas of the United States of America [27], [28]. The major advantage of this model is the use of several factors in association with other criteria to evaluate cyclist's perception of satisfaction of bicycle infrastructure. The BLOS is the outcome of research to validate the IHS [29]. In doing this, they employed about 150 bicyclists to reflect diverse cycling experiences, ages and socio-economic characteristics to ride round 30 distinctly selected roadway segments in Tampa, Florida. Each segment of the roadway was rated by bicyclists as they rode around. In order to provide insight into the ability of transportation planners to evaluate the level of safety in intersections, the bicycle intersection safety index (ISI) was developed in North Carolina using video data and online safety ratings of 67 intersections [30]. Other variables include 'traffic volume, the number of lanes, the speed limit, the presence of a bike lane/parking and the presence of traffic control to a given rating for an intersection approach according to a six-point scale' [30].

This review summarises the application of different methodologies to examine the level of satisfaction of cyclists in many parts of the world. It further reveals that different approaches are adopted to reflect traffic and socioeconomic characteristics of the city under consideration, which remains the basis for our methodology to address perception issues. 


\section{METHODOLOGICAL APPROACH}

Two pilot surveys (Enschede and Bogota) were initially carried out to ascertain the validity, and operational feasibility of our methodology. Different layers of data were used in this study, principal among which were perceptions rating data for both segments and intersections; geometric, physical and operational characteristics of road infrastructure based on both measurement and observation data.

\subsection{Video production/editing}

Segment and intersections videos were produced at different times/days of the week. Some sampling criteria include land use characteristics, trails, ciclocarrils and ciclovia (Sunday cycling). Each segment was filmed for 20-40 seconds while riding a bicycle at a speed of about $10 \mathrm{~km} / \mathrm{h}$ using a camera strapped 45 degrees on the head. Curb lane variables such as bicycle pathway widths, curb lane motorised volume (veh/h) and vehicle speed $(\mathrm{km} / \mathrm{h})$, bicycle volume on segment, median width was recorded in addition to secondary data.

During editing, videos were reduced to between 10-16 seconds and an instant 'repeat mode' of same time to allow review by participants. All segments and intersections were also appropriately named at the beginning of each video and a 5 seconds break was introduced between intervals of successive videos.

\subsection{Video and satisfaction rating surveys}

Many researches have employed the video technique for bicyclist and pedestrian studies since the late 1980s after Whyte [31] pioneered the use of film to record pedestrian behaviour in New York. Jensen [32] employed the use of a Steadicam camera in his study of 'pedestrian and bicyclist level of service on road way segments in Copenhagen' and later shown to stakeholders for rating. In this study, a bicyclist LOS questionnaire (Spanish translation) was administered to respondents in the study area for socio-economic data and ratings of videos. Whereas the method has the perceived weakness to reflect fatigue, such may not constitute a large error since it takes about 16 minutes for the entire survey. The strength of this approach includes the ability to reach a wider response group with minimal risks; more cost effective than having to interview each respondent on site; and the ability to obtain relevant information on satisfaction level per road category.

The choice of segment is due to the need to ensure uniform demand, control and geometry of the road. This in real situations may be difficult along a road with more than one intersection; therefore, different criteria were adopted to guide the choice of segments to reflect different motorised and non-motorised transport characteristics based on earlier works cited in previous sections.

In terms of intersections, about 3-5 videotapes were made for every identified junction. In principle, therefore maximum of three videos can be produced in any route to reflect three kinds of intersection (that is, intersection connecting three, four or multiple roads). Only one of each intersection category was examined along a chosen route. Weighting is used for others of the same class and multiplied by the number in that type, which is used in the survey after editing. Each intersection was filmed for 10-15 seconds a few meters away as far as sight of the intersection variables were unhindered.

\section{DATA AND ANALYTICAL TECHNIQUES}

Different methods of estimation of LOS models exist. For example, Jensen [32] applied the ordinary generalised linear models (GLMs), cumulative logit models (CLMs), and ordinary probit models (OPMs) to develop bicycle and pedestrian models in his Copenhagen study. Hankey et al. [33] on the other hand employed both ordinary least square (OLS) and 
maximum likelihood estimation (MLE) of the regression statistics to estimate models of bicycle and pedestrian traffic in Minneapolis. Similarly, Providelo and da Penha Sanches [1] used the method of successive intervals to define traffic characteristics based on priority of users and potential users to evaluate bicycle infrastructure in Brazilian medium-sized cities. These and other studies form the background for our choice of analytical techniques.

To evaluate the level of satisfaction of bicyclists in the study area, a statistical method with the capabilities for choice ordered modelling involving ordered discrete data. Using the Genlin procedure in SPSS, ordered probit logit were fitted in the generalized linear models (GLMs). This allows the fitting of ordinal outcomes, such as perception of LOS as rated by our survey participants based on video experiment. It is an extension of ordinal least squares regression that generalizes linear regression and thus allows the linear model to be related to the dependent variable (in our case the overall rating of segments/intersection). It is a multinomial probability distribution with cumulative logit as link function. We can therefore define an unobserved variable, $\mathrm{z}$, to derive ordered probabilities which enable us to define our BLOS rankings. These rankings exist as a linear function with an observation, $\mathrm{n}$, in which:

$$
\mathrm{z}_{\mathrm{n}}=\boldsymbol{\beta} \mathbf{X}_{\mathrm{n}}+\varepsilon_{\mathrm{n}}
$$

where $\mathrm{n}$ is the number of participants' rating, in this case, 1,360 ratings of 16 segments and 680 ratings of 8 intersections; $X$ is defined as a vector variable used to determine LOS; $\beta$ is a vector of parameters estimate; and $\varepsilon$ is an independent random disturbance term. when we remove the subscript $\mathrm{n}$ from eqn (1) to simplify it and convert LOS to numerical scale, that is, from A-F or 1-6, [34] the estimate for the probit model implies that:

$$
\begin{gathered}
\mathrm{y}=1 \text { if } \mathrm{z} \leq 0 \\
\mathrm{y}=2 \text { if } 0<\mathrm{z} \leq \mu_{1} \\
\mathrm{y}=3 \text { if } \mu_{1}<\mathrm{z} \leq \mu_{2} \\
\mathrm{y}=4 \text { if } \mu_{2}<\mathrm{z} \leq \mu_{3} \\
\mathrm{y}=5 \text { if } \mu_{3}<\mathrm{z} \leq \mu_{4} \\
\mathrm{y}=6 \text { if } \mathrm{z} \geq \mu_{4},
\end{gathered}
$$

where $\mu=$ estimable parameters (thresholds) used to categorise observed variable y and estimate $\mu \& \beta$ jointly. If $\varepsilon$ in eqn (1) satisfies the assumption of independent normal distribution in all observations with $0 \& 1$ mean and variance respectively, an ordered probit model results with the selection probabilities below:

$$
\begin{gathered}
\mathrm{P}(\mathrm{y}=1)=\Phi(-\beta \mathrm{X}) \\
\mathrm{P}(\mathrm{y}=2)=\Phi\left(\mu_{1}-\beta \mathrm{X}\right)-\Phi(-\beta \mathrm{X}) \\
\mathrm{P}(\mathrm{y}=3)=\Phi\left(\mu_{2}-\beta \mathrm{X}\right)-\Phi\left(\mu_{1}-\beta \mathrm{X}\right) \\
\mathrm{P}(\mathrm{y}=4)=\Phi\left(\mu_{3}-\beta \mathrm{X}\right)-\Phi\left(\mu_{2}-\beta \mathrm{X}\right) \\
\mathrm{P}(\mathrm{y}=5)=\Phi\left(\mu_{3}-\beta \mathrm{X}\right)-\Phi\left(\mu_{3}-\beta \mathrm{X}\right) \\
\mathrm{P}(\mathrm{y}=6)=1-\Phi\left(\mu_{4}-\beta \mathrm{X}\right),
\end{gathered}
$$

where $\Phi($.$) is defined as the cumulative distribution function of standard normal distribution$ or simply represents the usual probit function.

Since 16 and 8 observations for segments and intersections respectively, are generated by each of the participants, there is therefore a likelihood for these observations to share unobserved effects. This violates the independent disturbance assumption in eqn (1). 
Table 1: Variable descriptions (as used in SPSS analysis).

\begin{tabular}{|c|c|}
\hline Variable & Variable description \\
\hline Dependent variable & $\begin{array}{l}\text { Perceived satisfaction rating of the cicloruta (for segment and intersection } \\
\text { surveys) based on six-point Likert ranging from } 1 \text { as highly satisfied to } 6 \\
\text { as highly dissatisfied }\end{array}$ \\
\hline $\begin{array}{l}\text { Participant's personal } \\
\text { characteristics }\end{array}$ & $\begin{array}{l}\text { Gender }(1=\text { Male; } 0=\text { Female }) \text { Age }(1=<35 ; 0=>35) \\
\text { Localidad }(1=\text { Barrios Unidos; } 2=\text { Teusaquillo; } 3=\text { Puente Aranda; } 4=\text { Los } \\
\text { Martires; } 5=\text { Antonio Narino; } 6=\text { Tunjuelito; } 7=\text { Rafael Uribe; } 8=\text { Candelaria; } \\
\text { 9=Santa Fe; } 10=\text { Suba; } 11=\text { Usaquen; } 12=\text { Chapinero; } 13=\text { Kennedy; } \\
\text { 14=Engativa; } 15=\text { Fontibon; } 16=\text { Bosa; } 17=\text { San Christobal; } 18=\text { Usme; } \\
\text { 19=Sumapaz; } 20=\text { Cuidad Bolivar) } \\
\text { Housing type }(5=\text { Detached; } 6=\text { Terraced; } 7=\text { Flat; } 8=\text { Student hostel; } \\
\text { 9=Other) } \\
\text { Bicycle ride in Bogota city ( } 1=\text { Yes; } 0=\text { No) } \\
\text { Number of bicycle trips undertaken }(1=<5 ; 2=5-10 ; 3=10+)\end{array}$ \\
\hline Experience & $\begin{array}{l}\text { Number of } \mathrm{km} / \text { week with bike }(5=<10 ; 6=10-15 ; 7=16-29 ; 8=30-45 ; \\
9=46+) \\
\text { Experience in riding ( } 1=\text { Experienced; } 0=\text { Inexperienced }) \\
\text { If yes, how many } \mathrm{km} \text { do you ride to work/school; shopping; recreation; } \\
\text { other }\end{array}$ \\
\hline $\begin{array}{l}\text { Environmental } \\
\text { characteristics }\end{array}$ & $\begin{array}{l}\text { What percentage of your riding is done in major roads; residential streets; } \\
\text { cicloruta; sidewalks; and other road facilities? } \\
\text { Does weather affect your decision to use bicycle? }(1=\mathrm{Yes} ; 0=\mathrm{No})\end{array}$ \\
\hline Segment variables & $\begin{array}{l}\text { If yes; rain; drizzle; steady rain; heavy rain; fog; hot weather }(1=\text { Yes; } 0=\text { No } \\
\text { for each) } \\
\text { Bicycle lane width (BLW): } 1=>2 \mathrm{~m} ; 0=<2 \mathrm{~m} \\
\text { Wide outside lane (WOL): } 1=<10 \mathrm{ft} ; 0=>10 \mathrm{ft} \\
\text { Pavement condition of lane (PCL): } 1=\mathrm{Good} ; 0=\text { otherwise } \\
\text { Side path separation (SPS): } 1=\text { present; } 0=\text { otherwise } \\
\text { Number of through lanes (NTL): } 1 \leq 2 \text { lanes; } 0=\text { otherwise } \\
\text { Vehicle speed (VS): } 1 \leq 30 \mathrm{mi} / \mathrm{hr} ; 0=\text { otherwise } \\
\text { Motorised traffic volume (MTV): } \leq 600 \text { cars } / 15 \mathrm{~min} ; 0=\text { otherwise } \\
\text { Conflicts with pedestrian (CWP): } 1=\leq 10 \text { conflicts; } 0=\text { otherwise }\end{array}$ \\
\hline Intersection variables & $\begin{array}{l}\text { Tree and benches }(\mathrm{TB}): 1=\text { trees/benches/grasses; } 0=\text { otherwise } \\
\text { Daylight: } 1=\text { daytime; } 0=\text { otherwise } \\
\text { Volume of cyclists (VOC): } 1=\geq 2 \text { cyclists; } 0=\text { otherwise } \\
\text { Conflicts with pedestrian/cyclists }(\mathrm{CPC}): 1=\leq 3 \text { conflicts } \\
\text { Road signs and markings (RSM): } 1=\text { signs/markings present; } 0=\text { otherwise } \\
\text { Total intersection legs (TIL: } 1=31 \text { eg; } 0=\text { otherwise } \\
\text { Crossing width of intersection }(\mathrm{CWI}): 1 \leq 12 \mathrm{ft} ; 0=\text { otherwise }\end{array}$ \\
\hline
\end{tabular}

We therefore adopt the traditional random effects to address this effect. It is where an individual-specific term $\varphi$ i included in other to rewrite eqn (1), thus:

$$
\mathrm{zn}=\boldsymbol{\beta} \mathbf{X i c}+\varepsilon \mathrm{ic}+\varphi \mathrm{i},
$$

where subscript I denotes the index of individual participant; subscript $\mathrm{c}$ as index of video clips; while all other terms are as earlier defined [4].

In this study, a generalised random parameter approach is preferred because of the very subjective nature of satisfaction or comfort, in which our rating data is obtained. In this sense, the model is generalised for each of the survey participants to have its own $\beta_{\mathrm{i}}$. For each respondent therefore, $\mathrm{i}, \beta_{\mathrm{i}}$ is estimated as a random and fixed term, written as: 


$$
\boldsymbol{\beta}=\boldsymbol{\beta}+\mathrm{w}_{\mathrm{i}},
$$

where $\boldsymbol{\beta} \mathbf{i}$ is a vector of specific individual parameters, $\mathrm{w}_{\mathrm{i}}$ is a disturbance term for the random distribution [35].

\subsection{Segment Bicycle Level of Service (BLOS)}

Initial development and calibration of BLOS was done at the roadway segment level. Our segment LOS is defined as BLOS score for every named segment. The estimated model (1) is used to calculate the LOS score for each segment and cicloruta in ArcGIS. We further aggregate our segment BLOS (about 584 segments) into ciclorutas (71) based on their name ID. It is important to note that different segments of the cicloruta share similar names irrespective of their categorisation. To make our scores amenable for facility BLOS estimation therefore, we averaged all scores of similar ciclorutas using:

$$
\mathrm{AVBLOS}_{\text {segment }}=\sum \mathrm{BLOS}_{\text {segment }} 1+2+3+4, \ldots ., \mathrm{n} / \mathrm{N},
$$

where AVBLOSsegment = average BLOS score for cicloruta sharing similar name ID; $\mathrm{n}=$ nth number of ciclorutas; and $\mathrm{N}=$ total number of segments (see Fig. 1).

\subsection{Intersection Bicycle Level of Service (IntBLOS)}

For us to have an estimation that more readily reflects the true bicycle transport conditions in Bogota, the study also examined the LOS of intersections as part of the cicloruta system. Few studies that estimated intersection BLOS exist [30], [36], [37] and even fewer have considered a joint estimation of intersection and segment. Carter et al. [30] developed an intersection safety index for North Carolina using the generalised linear models, while Landis et al. [36] developed a Pearson Correlation and Factor Analysis-based methodology in estimating intersection LOS for the Florida Department of Transportation (FDoT). Some of these studies provided background for choice of intersection variables which were revised to reflect local transport conditions in Bogota. Similar analytical approach as in segment analysis also applies in the estimation of intersections BLOS (Fig. 1).

\subsection{Facility LOS}

To achieve the objective of this study, a LOS score is estimated at the facility level. This is needed because current transportation planning programs emphasize LOS at facility level since roadway segments are not independent of the entire network. For example, FDOT [21] and Greene and Hensher [34] developed a BLOS model that aggregates individual bicycle segment analyses into a 'facility'. This is particularly important in view of the fact that there is hardly any continuity in paved shoulder/bicycle track existence over the entire road facility. Some portions may offer reasonably good facilities while others will not, to the extent of discouraging bicyclists. The nature of cicloruta is not consistent with any particular pattern and therefore makes it imperative to make adjustments to earlier formulated theory on estimation of LOS at facility level. The final estimation is carried out thus:

$$
\mathrm{BLOS}_{\text {facility }}=\frac{\sum \mathrm{BLOS}_{\mathrm{segment}}}{\mathrm{n}}+\sum \mathrm{BLOS}_{\mathrm{intersection}} / 2,
$$

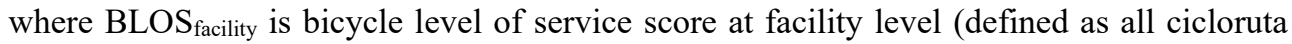
sharing similar name identity irrespective of their categorisation; $\sum B L O S_{\text {segment }}$ is bicycle 
level of service score at segment level; $\mathrm{n}$ is the number of segments in that facility; and $\sum B L O S_{\text {intersection }}$ is bicycle level of service score at intersection level.

Estimation of LOS at all three levels is matched against LOS scores shown in Table 2. This is as contained in the highway capacity manual, a modification of Landis [27] and Landis et al. [36]. Our initial rating values and other measurement data are now converted into parameter estimates and coefficients and are therefore comparable to the table values (Table 2). At the facility level therefore, about 71 ciclorutas have their BLOS estimated to provide a methodology for future estimation, facility maintenance and upgrade of the cycling network.

\section{MODEL APPLICATIONS}

\subsection{Estimation results of Model 1}

Preliminary investigations showed a strong correlation between dependent variables and independent variable at 0.05 level of significance. Our model is considered a good fit because deviance (1.085) is close to the value of 1 [35]. Using eqn (5), we therefore estimated parameters for each observation and the result shows that parameters vary across participants (Table 3). Positive parameters in the table mean that a unit change would lead to a higher probability to get a less favourable LOS ranking, while negative parameters on the other hand mean that a unit change in the variable leads to a higher probability that a more favourable LOS will be perceived by participants. The validity of these estimates confirms they did not occur by chance. The sample error was tested at 005 level of significance. Some of the parameters found to vary across respondents (random) included side path separation (SPS), vehicle speed (VS), motorised traffic volume (MTV), conflicts with pedestrian (CWP), daylight, gender, and age. They are normally distributed with standard deviation significantly different from zero. We therefore conclude that they provide a more superior statistical fit to the data since their significant value is less than our confidence interval of 0.05 , even though other variables are considered for random parameters, they provide inferior statistical fit (Table 3).

Recall that our satisfaction levels ranges from 1 for highly satisfied to 6 for highly dissatisfied. Therefore, in our estimated parameters (Table 3), the probability to rate or derive a HS level increases the ordered logit by 0.187 or is exponentiated at 1.205 less likely than other levels of satisfaction. The same cannot be said about other levels of satisfaction as these are statistically significant at 0.05 confidence interval, where AS, MS, MD, AD and HD are respectively exponentiated at 2.789, 4.957, 7.189, 11.416 and 19.196 less likely than other levels of satisfaction. We therefore develop our estimation model using our parameters and factors that are statistically superior in their contribution to the level of satisfaction rating (Table 4). About 15 variables comprising of 13 factors and 2 covariates were initially used in the estimation.

However, only 7 were statistically superior to fit the model at 0.05 confidence interval (Table 3). They include 4 measurement variables (SPS, VS, MTV and CWP), 1 environmental variable (daylight), and 2 socio-economic variables (age and gender). In estimating our model therefore, only the 4 statistically significant variables were used. These include: SPS; VS; MTV; and CWP. Gender and age showed statistical significance but could not be used in the model as these are used as covariate in our model estimation process.

Daylight although statistically significant, could not be used as it is an environmental variable whose changes are obvious, day and night. The results however underscore the preferred time of cycling in the study area which may not be unconnected with safety issues. 


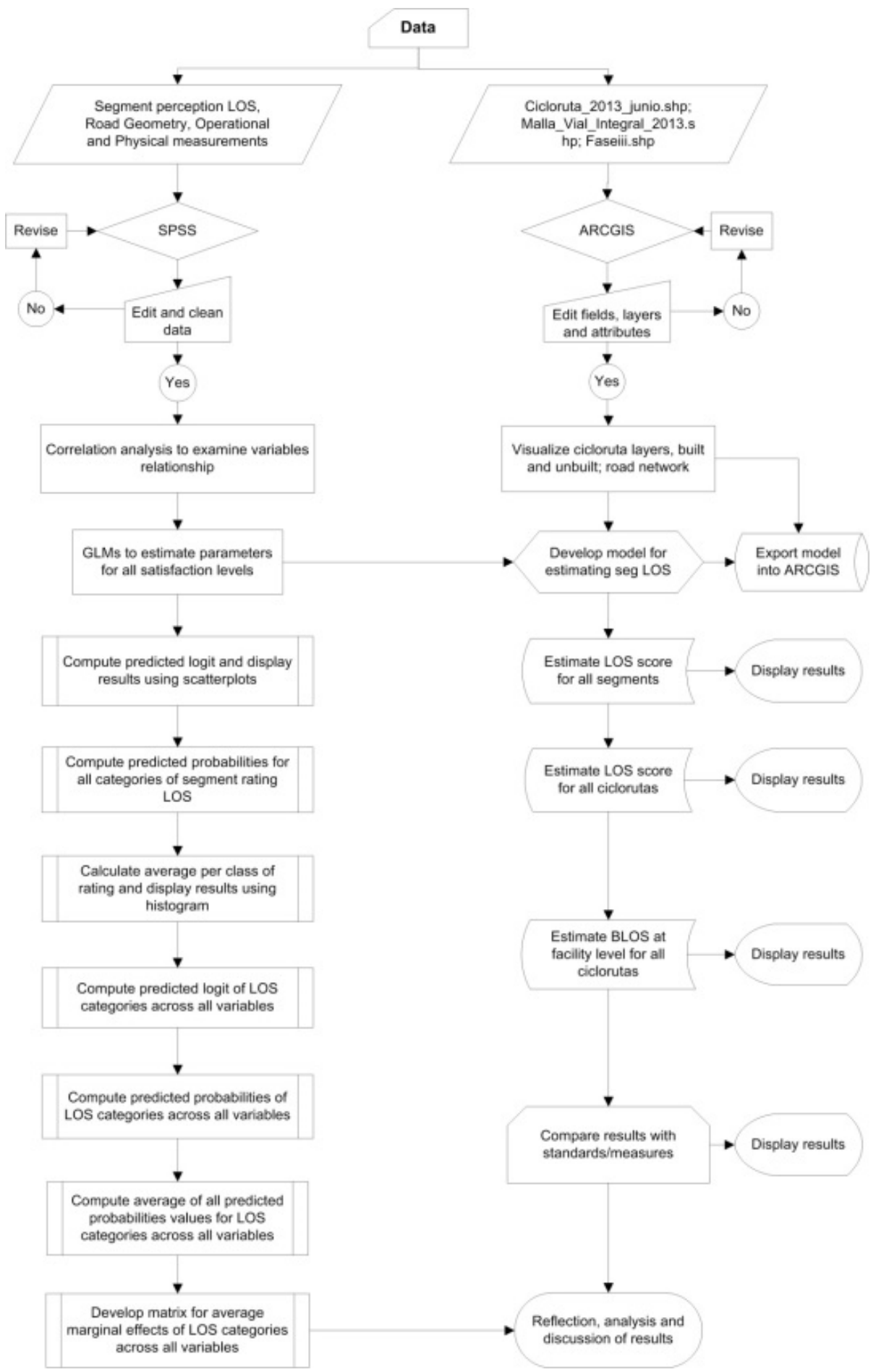

Figure 1: Flowchart of methodology for segment and intersection LOS estimation. 


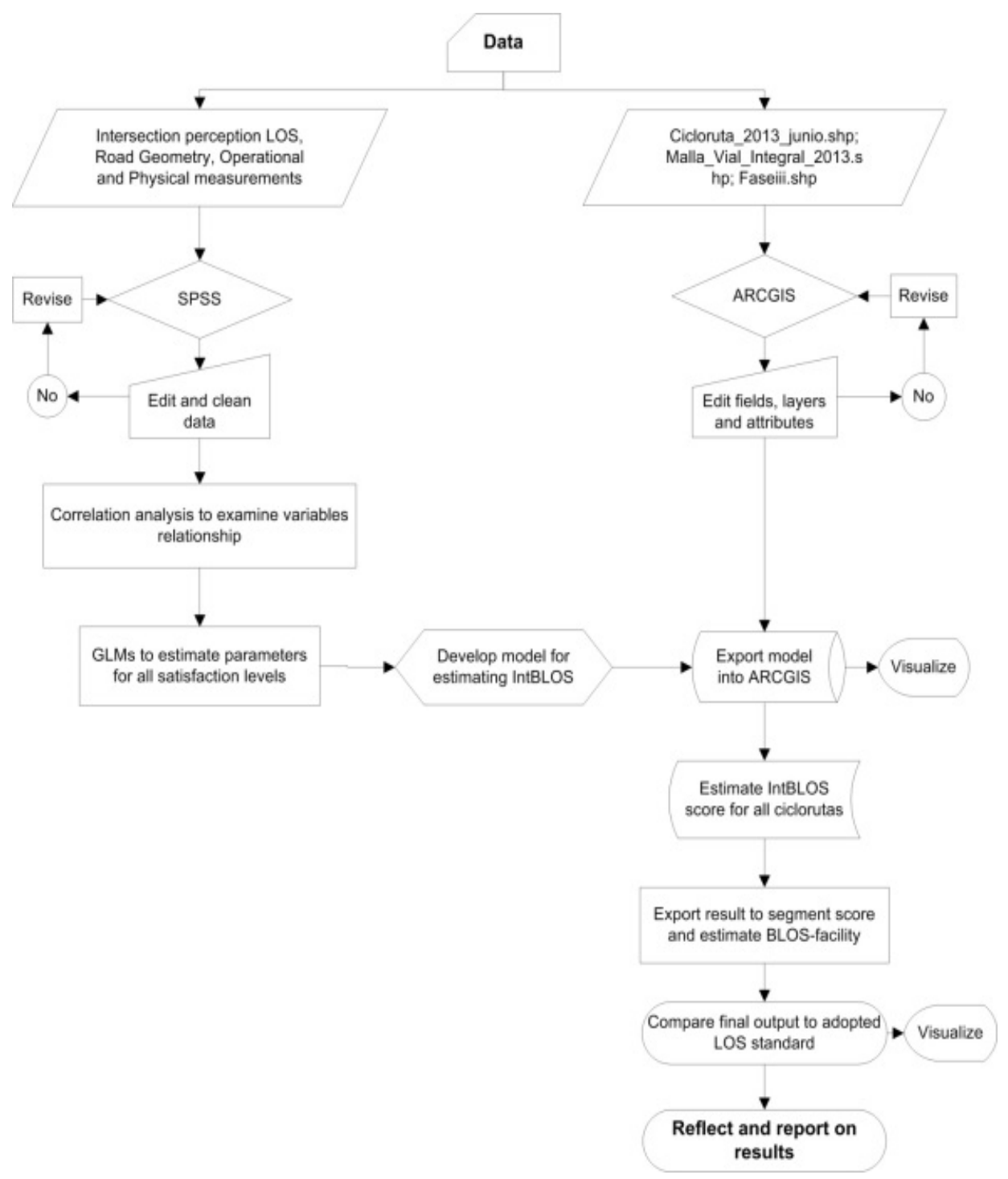

Figure 1: Continued.

Table 2: LOS scores (after HCM [35]).

\begin{tabular}{lll}
\hline LOS & Score & Description \\
A & $\leq 2.00$ & Excellent \\
B & $>2.00-2.75$ & Very good \\
C & $>2.75-3.50$ & Good \\
D & $>3.50-4.25$ & Fair \\
E & $>4.25-5.00$ & Poor \\
F & $>5.00$ & Very poor \\
\hline
\end{tabular}


Table 3: Random parameters ordered probit model of bicyclists perceived level of service (segments).

\begin{tabular}{|c|c|c|c|c|}
\hline Variable description & $\begin{array}{c}\text { B } \\
\text { (Parameter est.) }\end{array}$ & $\begin{array}{c}\text { Exp (B) } \\
\text { (Var of est.) }\end{array}$ & $\begin{array}{l}\text { Wald } \\
\text { Chi-Sq }\end{array}$ & Sig. \\
\hline Threshold 1 & 0.187 & 1.205 & 1.925 & 0.165 \\
\hline Threshold 2 & 1.024 & 2.784 & 55.647 & 0.000 \\
\hline Threshold 3 & 1.601 & 4.957 & 129.666 & 0.000 \\
\hline Threshold 4 & 1.973 & 7.189 & 190.072 & 0.000 \\
\hline Threshold 5 & 2.435 & 11.416 & 279.138 & 0.000 \\
\hline Threshold 6 & 2.955 & 19.196 & 395.655 & 0.000 \\
\hline $\operatorname{BLW}(1=<2 \mathrm{~m} ; 0>2 \mathrm{~m}=)$ & -0.126 & 0.882 & 0.487 & 0.485 \\
\hline WOL $(1=<10 \mathrm{ft} ; 0=>10 \mathrm{ft})$ & -0.451 & 0.637 & 0.189 & 0.663 \\
\hline PCL (1=Good; 0=otherwise) & -0.114 & 0.893 & 0.012 & 0.914 \\
\hline SPS ( $1=$ present; $0=$ otherwise $)$ & 0.605 & 1.831 & 29.946 & 0.000 \\
\hline NTL ( $1 \leq 2$ lanes; $0=$ otherwise $)$ & 0.726 & 2.066 & 0.486 & 0.486 \\
\hline VS $(1 \leq 30 \mathrm{mi} / \mathrm{hr} ; 0=$ otherwise $)$ & 0.717 & 2.049 & 49.859 & 0.000 \\
\hline $\operatorname{MTV}(\leq 600 \mathrm{cars} / 15 \mathrm{~min} ; 0=$ otherwise $)$ & -0.381 & 0.683 & 10.976 & 0.001 \\
\hline CWP $(1=\leq 10$ conflicts; $0=$ otherwise $)$ & 1.173 & 3.231 & 156.831 & 0.000 \\
\hline $\mathrm{TB}(1=$ trees/benches $/$ grasses; $0=$ otherwise $)$ & -0.038 & 0.963 & 0.105 & 0.746 \\
\hline DAYLIGHT (1=daytime; $0=$ otherwise) & 0.473 & 1.605 & 9.700 & 0.002 \\
\hline RAIN (1=Rain; 0=otherwise) & -0.026 & 0.974 & 0.180 & 0.671 \\
\hline RIDE ( $1=$ Ride in city; $0=$ otherwise $)$ & 0.118 & 1.125 & 3.466 & 0.936 \\
\hline EXPERIENCE ( $1=$ Yes; $0=$ otherwise $)$ & 0.005 & 1.005 & 0.006 & 0.063 \\
\hline GENDER ( $1=$ Male; $0=$ Female $)$ & -0.262 & 0.769 & 18.219 & 0.000 \\
\hline AGE & 0.473 & 1.604 & 27.064 & 0.000 \\
\hline Number of observations & 1,360 & & & \\
\hline Log likelihood chi-square & $4.55 .322(0.000)$ & & & \\
\hline Deviance & $1773.484(1.085)$ & & & \\
\hline Scaled Deviance & 1773.484 & & & \\
\hline Pearson Chi-Square & $3774.940(2.309)$ & & & \\
\hline Scaled Pearson Chi-Square & 3774.940 & & & \\
\hline Log likelihood & -1257.919 & & & \\
\hline Akaike’s Information Criteria (AIC) & 2557.839 & & & \\
\hline Finite Sample Corrected AIC (AICC) & 2558.529 & & & \\
\hline Bayesian Information Criteria (BIC) & 2667.359 & & & \\
\hline Consistent AIC (CAIC) & 2688.359 & & & \\
\hline
\end{tabular}

Dependent variable responses are integers ranging from 1-6 for A-F (highly satisfied-highly-dissatisfied).

Table 4: Model 1.

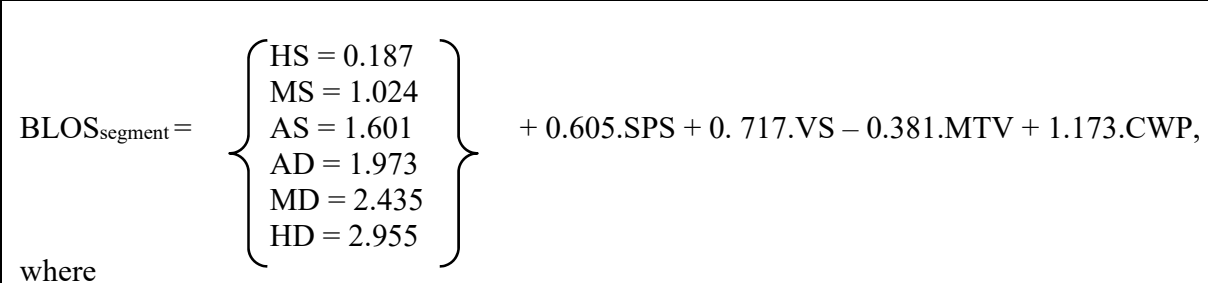

$\mathrm{HS}=$ highly satisfied; $\mathrm{MS}=$ moderately satisfied; $\mathrm{AS}=\mathrm{a}$ little satisfied; $\mathrm{AD}=\mathrm{a}$ little dissatisfied; $\mathrm{MD}=$ moderately dissatisfied; $\mathrm{HD}=$ highly dissatisfied; $\mathrm{SPS}=$ side path separation; VS = vehicle speed; $\mathrm{MTV}=$ motorized through volume; and $\mathrm{CWP}=$ conflicts with pedestrian and other cyclists. 
This means that there are other important considerations for cycling satisfaction, apart from the four variables above. In Fig. 2, results of the BLOS estimation at segment and cicloruta (facility) level reveal minimum difference since scores are aggregated to grades (see Table 2). Most ciclorutas adjoining Avenida El Dorado (West of Bogota) just as others in the north and south-west are revealed to score B grade. No cicloruta secured an 'A' grade in both results, which may not necessarily mean that no cyclist derives the highest satisfaction level from the use of specific segments of the cicloruta. The probable reason may be use of averages in our model estimation. This is one of the weaknesses of our method whose initial procedure (predicted logit) produced a sigmoid-curve scatter plot across all BLOS category responses. It is somewhat like the s-shape curve in logistic regression and reveals satisfaction level of participants based on unit changes in all variables combined.

\subsection{Estimation results of Model 2}

A similar statistical procedure for estimating the segment BLOS was adopted for intersection BLOS. Some geometry, physical and traffic operational characteristics such as the volume of cyclists, conflicts with other cyclists and pedestrians at intersections, road signs/markings at intersections, total intersection legs, and crossing width of intersections were used in addition to ratings (Table 5). Experience and bicycle ridership in the city were used as covariates in the estimation process.

Since the level of experience is subjective based on personal opinion, it was excluded from the model just as gender that was used as covariate, even though they were statistically significant. We have earlier observed our perception intersection BLOS as ' $E$ ' for all three kinds of intersections (Table 5). The model in Table 6 is used in ArcGIS to display estimation of intersection BLOS. Earlier results of parameter estimates (Table 5).

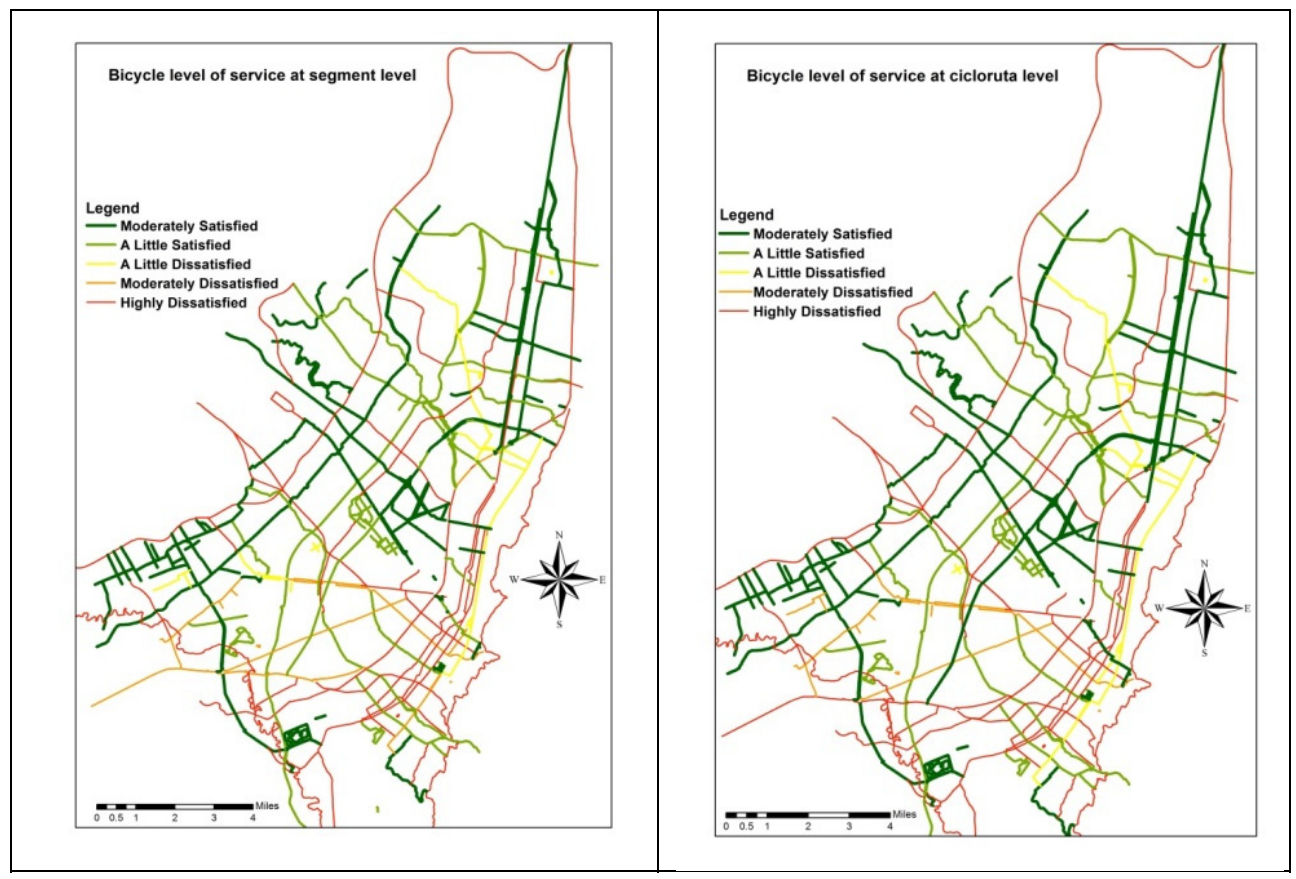

Figure 2: Estimated BLOS at both segment and cicloruta levels. 
Table 5: Random parameters ordered probit model of bicyclists perceived LOS (intersections).

\begin{tabular}{|c|c|c|c|c|}
\hline Variable description & $\begin{array}{c}\text { B } \\
\text { (Parameter est.) }\end{array}$ & $\begin{array}{c}\text { Exp (B) } \\
\text { (Var of est.) }\end{array}$ & $\begin{array}{l}\text { Wald Chi- } \\
\text { Square }\end{array}$ & Sig. \\
\hline Threshold 1 & -2.960 & 0.052 & 53.719 & 0.000 \\
\hline Threshold 2 & -1.568 & 0.209 & 39.848 & 0.000 \\
\hline Threshold 3 & -0.680 & 0.506 & 8.110 & 0.004 \\
\hline Threshold 4 & 0.017 & 1.017 & 0.005 & 0.944 \\
\hline Threshold 5 & 0.792 & 2.208 & 10.955 & 0.001 \\
\hline Threshold 6 & 2.024 & 7.565 & 65.240 & 0.000 \\
\hline $\operatorname{VOC}(1=\geq 2$ cyclists & 1.116 & 3.053 & 46.354 & 0.000 \\
\hline crossing $; 0=$ otherwise) & 1.048 & 2.851 & 59.851 & 0.000 \\
\hline $\mathrm{CPC}(1=\leq 3 ; 0=$ otherwise $)$ & 0.079 & 1.082 & 0.123 & 0.726 \\
\hline $\operatorname{RSM}(1=\mathrm{RSM}$ present; $0=$ otherwise $)$ & -0.365 & 0.694 & 5.221 & 0.022 \\
\hline $\operatorname{TIL}(1=3$ legs; $0=$ otherwise $)$ & -0.111 & 0.895 & 0.291 & 0.590 \\
\hline CWI $(1=\leq 12$ feet; $0=$ otherwise $)$ & -0.465 & 0.628 & 25.934 & 0.000 \\
\hline EXPERIENCE ( $1=$ Yes; $0=$ otherwise) & 0.160 & 1.174 & 3.293 & 0.070 \\
\hline $\operatorname{RIDE}(1=$ Ride in city; $0=$ otherwise $)$ & 0.022 & 1.022 & 0.033 & 0.856 \\
\hline AGE & -0.534 & 0.586 & 38.093 & 0.000 \\
\hline GENDER ( $1=$ Male; $0=$ Female $)$ & 860 & & & \\
\hline Number of observations & $131.619(.000)$ & & & \\
\hline Log likelihood chi-square & $371.496(.820)$ & & & \\
\hline Deviance & 371.496 & & & \\
\hline Scaled Deviance & $351.348(.776)$ & & & \\
\hline Pearson Chi-Square & 351.348 & & & \\
\hline Scaled Pearson Chi-Square & -363.679 & & & \\
\hline Log likelihood & 757.358 & & & \\
\hline Akaike's Information Criteria (AIC) & 758.081 & & & \\
\hline Finite Sample Corrected AIC (AICC) & 825.189 & & & \\
\hline $\begin{array}{l}\text { Bayesian Information Criteria (BIC) } \\
\text { Consistent AIC (CAIC) }\end{array}$ & 840.189 & & & \\
\hline
\end{tabular}

Dependent variable responses are integers ranging from 1-6 for A-F (HS to HD).

Table 6: Model 2.

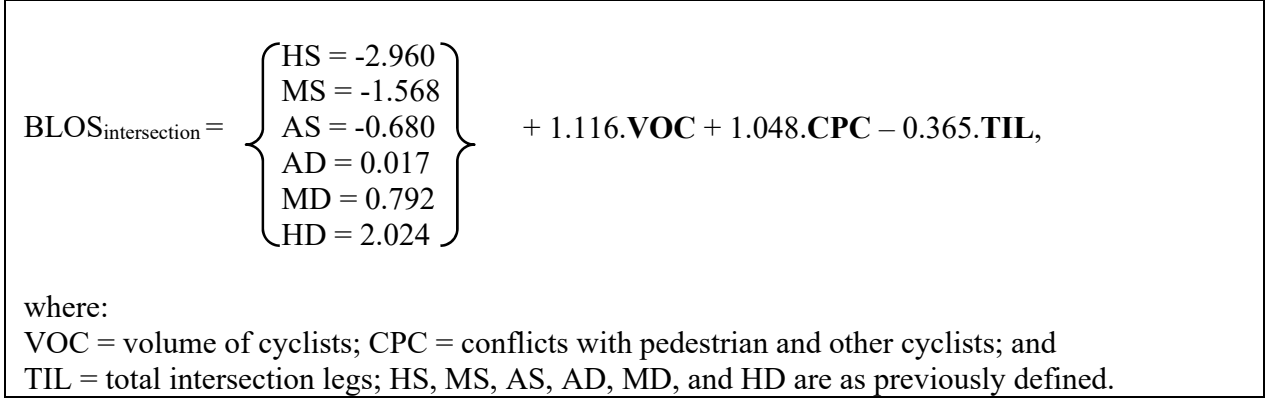

reveal three variables as making superior contribution to the model. They include volume of cyclists, conflicts with pedestrian and other cyclists; and total intersection legs. The predicted logit produced a sigmoid-curve scatter plot across all BLOS category responses. It reveals 
satisfaction levels of participants based on unit changes in all variables combined, whereas the graph shows perception rating of satisfaction of segments of the cicloruta in comparison with estimated scores of satisfaction level.

In other to validate our methodology, we sampled 33 intersections from 3 ciclorutas namely Avenida Boyoca, Avenida Ciudad De Cali and Las Aquas-Av El Dorado. Model 2 is used in ArcGIS to estimate both intersection BLOS and facility BLOS in accordance with eqns (6) and (7). Average intersection scores for all three ciclorutas included 3.0912, 3.1759 and 2.9325 respectively. Fig. 3(a) shows intersection BLOS in the cicloruta network and road network (major arterials). The effectiveness of this methodology is expressed with sampled segments showing the level of satisfaction derived from use of every intersection across a given path. The second map in the figure reveals the BLOS score at facility level, given as average BLOS plus average intersection BLOS divided by two (eqn 8). Avenida Boyoca with AvBLOS score of 3.3492 has BLOS facility of 3.2202 equivalent to grade 'C' Avenida Ciudad De Cali on the other hand with 2.33 AvBLOS has 2.7529 BLOS $_{\text {facility }}$ or ' $C$ ' grade. This underscores the weakness of the grading system as this cicloruta is only 0.0529 points away from its earlier ' $\mathrm{B}$ ' grade. Moreover, Las Aquas-Av El Dorado also scored ' $\mathrm{C}$ ' grade or $2.7616 \mathrm{BLOS}_{\text {facility }}$ from its earlier AvBLOS score of 2.5907.

Some earlier methodologies [37] incorporated right turn through traffic and left turn for opposite traffic. Other variables include specific design of intersections and length of segments between intersections. The scope of this study could not consider these variables in the model since some operational variables are already considered in segment BLOS. This methodology is therefore confirmed to be effective in view of the complex nature of intersections in the study area.

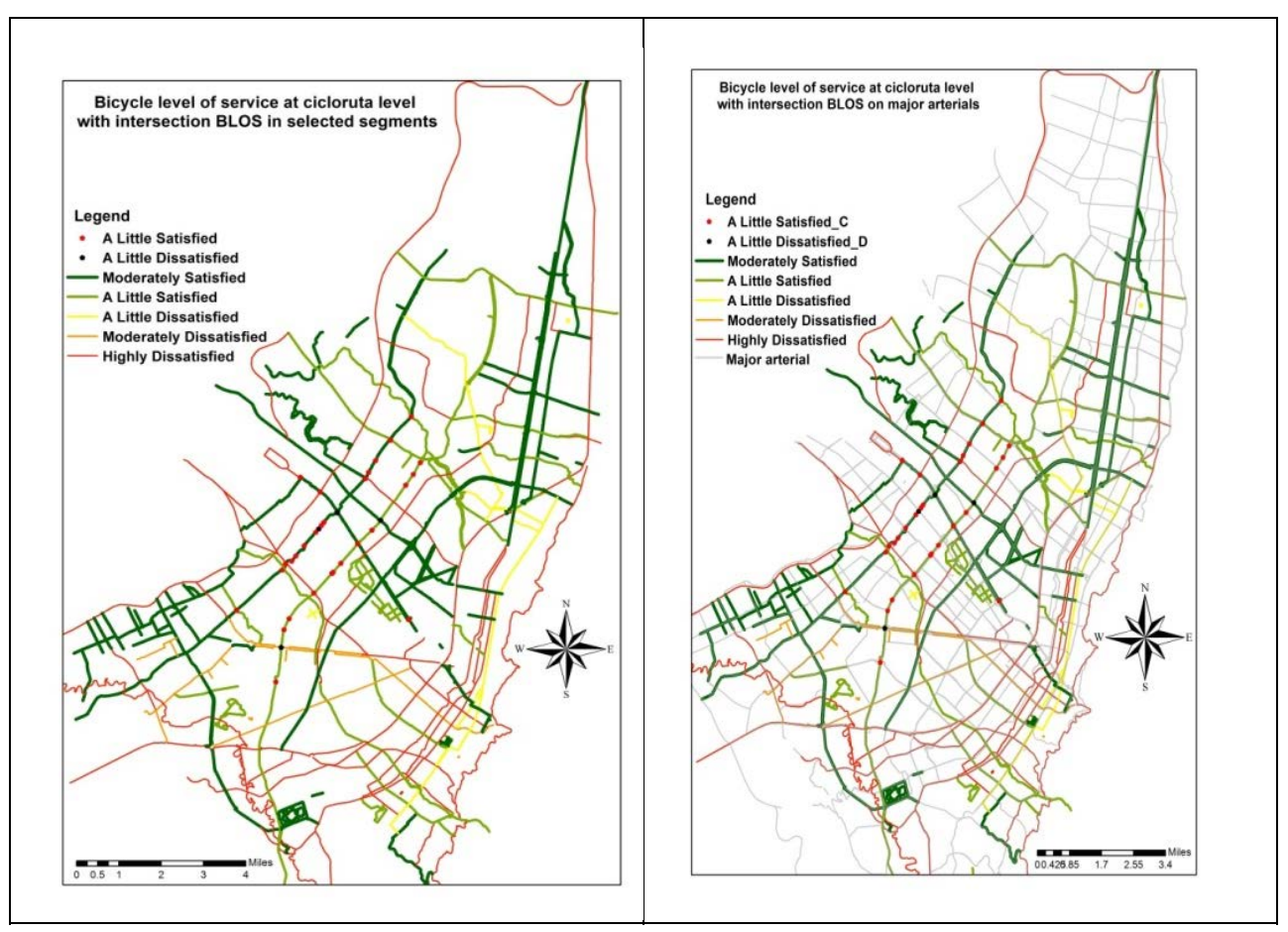

Figure 3: (a) Intersection BLOS (segment); and (b) Intersection BLOS (arterial). 


\section{CONCLUSIONS AND RECOMMENDATIONS}

Some important findings can be found in the estimation of the two models not just in terms of contributor variables to satisfaction but also in the empirical findings of the magnitude of these effects across the study population. Important elements include the significance of side path separation in the perception of safety of cyclists. The findings suggest that adequate attention be directed at planning for physical separation of bicycle paths from motorised traffic. Such facilities like raised curb shoulder, planting of trees and grasses and use of physical barriers can be useful. Secondly, vehicle speed also has a significant impact on the satisfaction of bicyclists. This is not unrelated with cases of vehicle and bicyclists' collisions as explained by many interviewed residents. The lack of posted speed limits and an effective policy to regulate speed in the city corroborates bicyclists' fears. Thirdly, motorised traffic volume affects the safety feeling of cyclists. The variable odd ratio value is negative meaning that a unit increase in the MTV increases the probabilities for a higher level of satisfaction. This can be explained by the feeling of safety and security of property that cyclists enjoy as many areas of the city are said to be unsafe for cycling. Finally, conflicts with pedestrian and other cyclists, physical barriers separating lanes and other non-motorised four-wheeled modes affect the level of cyclists' satisfaction.

The concept of bicyclists' level of satisfaction is not rigorously defined in this study and therefore it is expected that perception of satisfaction would vary considerably across all participants. It is in view of this uncertainty regarding the concept of satisfaction that this research opted for a statistical approach that deals with probabilities. The study has provided an empirical methodology for estimating the level of satisfaction that bicyclists derive from the use of the cicloruta. The findings confirm the validity of the use of video data in combination with other geometry, physical and operational traffic characteristics.

The proposed model therefore represents a BLOS methodology for evaluating bicycle infrastructure in Bogota. This represents alternative solutions which seek encouragements for cycling as a mode of transport. It is however believed that this model would be useful not only in Bogota but also in South America and indeed elsewhere in the world as an effective tool for bicycle infrastructure planning. An expansion and further improvement is possible to reflect peculiar transport circumstances of different cities. Further testing for the significance of model variables such as side path separation, vehicle speed, motorised traffic volume and conflicts with pedestrians is also possible. The output of this research can become a vital component of data for routing of ciclorutas along slope, best route and shortest path along good ciclorutas and so on. Future studies would have to enlarge the scope of this paper to fully understand the satisfaction level of cyclists and potential users on the quality of infrastructure for bicycling. Other methods that seek to focus on different profile of bicyclists are recommended. However, based on the methodology and result of this research, further studies on accessibility on the cicloruta and associated land uses can also be carried out.

Much needs to be done to enlighten cyclists on safety issues such as speed. Proper enlightenment should be directed at motorists on the right of the cyclist especially in shared lanes like the ciclocarrils while programmes that highlight the dangers of speed should also be emphasized. Bicycle use amongst children of school going age should be encouraged to inculcate in the young people the culture of cycling. In this regard, there should be an improved effort to develop suitable programmes in the school curriculum that highlight some of these issues among road users irrespective of age, sex and income. Enlightenment programmes should also be directed at all urban residents on the need to respect traffic separation. This is in view of the frustrations cyclist face with regular conflicts with pedestrian and other modes almost across the entire network. 


\section{ACKNOWLEDGEMENTS}

The contribution of staff/management of Humana Bogota, Instituto de Desarrollo Urbano (IDU), IDECA, Piloto University, Los Andes University, Rosario University, Despacio and Movilidad is well acknowledged.

In particular, we want to dedicate this work to Cesar Criollo, who was brutally murdered on the $29^{\text {th }}$ December 2014, while riding his bike in Flandes municipality, Cundinamarca. Cesar was instrumental in planning and arranging the section rides in the fieldwork data collection and took part in many data collection activities. Without his inputs, this research would not have been possible. May he rest in peace.

\section{REFERENCES}

[1] Providelo, J.K. \& da Penha Sanches, S., Roadway and traffic characteristics for bicycling. Transportation, 38(5), pp. 765-777, 2011.

[2] Asadi-Shekari, Z., Moeinaddini, M. \& Zaly Shah, M., Non-motorised Level of Service: Addressing Challenges in Pedestrian and Bicycle Level of Service. Transport Reviews, 33(2), pp. 166-194, 2013.

[3] KMOCT., Korean highway capacity manual, Korean Ministry of Construction and Transportation. Gwacheoun-si, 2001.

[4] Kang, K. \& Lee, K., Development of a bicycle level of service model from the user's perspective. KSCE Journal of Civil Engineering, 16(6), pp. 1032-1039, 2012.

[5] Bauman, A., Phongsavan, P., Schoeppe, S. \& Owen, N., "Physical activity measurement-a primer for health promotion." Promotion \& Education, 13(2), pp. 92-103, 2006.

[6] Dixon, L.B., Bicycle and pedestrian level-of-service performance measures and standards for congestion management systems. Transportation Research Record: Journal of the Transportation Research Board, 1538(1), pp. 1-9, 1996.

[7] Landis, B.W., Vattikuti, V.R. \& Brannick, M.T., Real-time human perceptions: toward a bicycle level of service. Transportation Research Record: Journal of the Transportation Research Board, 1578(1), pp. 119-126, 1997.

[8] Hook, W., Automobile dependency and the global cultural war: Lessons from Bogota. Sustainable Transport, 16, pp. 1-3, 2004.

[9] Skinner, R., City profile: Bogota. Cities, 21(1), pp. 15-22, 2004.

[10] Massink, J., Estimating the climate value of bicycling in Bogotá, Colombia, using a shadow pricing methodology. Master's thesis, University of Twente, 2009.

[11] Gatersleben, B. \& Appleton, K.M., Contemplating cycling to work: Attitudes and perceptions in different stages of change. Transportation Research Part A: Policy and Practice, 41(4), pp. 302-312, 2007.

[12] Landis, B.W., Bicycle interaction hazard score: a theoretical model. Transportation Research Record 1438, TRB, National Research Council, Washington, DC, pp. 3-8, 1994.

[13] Cavill, N. \& Davis, A., Cycling and health-what's the evidence? Transportation Research Board, 2007.

[14] Litman, T., Introduction to Multi-Modal Transportation Planning. Victoria Transport Policy Institute, 15, 2011.

[15] Larsen, J., Patterson, Z. \& El-Geneidy, A., Build it. But where? The use of geographic information systems in identifying locations for new cycling infrastructure. International Journal of Sustainable Transportation, 7(4), pp. 299-317, 2013. 
[16] Dill, J. \& Carr, T., Bicycle commuting and facilities in major US cities: if you build them, commuters will use them. Transportation Research Record: Journal of the Transportation Research Board, 1828(1), pp. 116-123, 2003.

[17] Rietveld, P. \& Daniel, V., Determinants of bicycle use: do municipal policies matter? Transportation Research Part A: Policy and Practice, 38(7), pp. 531-550, 2004.

[18] Wardman, M., Hatfield, R. \& Page, M., The UK national cycling strategy: can improved facilities meet the targets? Transport Policy, 4(2), pp. 123-133, 1997.

[19] Tilahun, N.Y., Levinson, D.M. \& Krizek, K.J., Trails, lanes, or traffic: Valuing bicycle facilities with an adaptive stated preference survey. Transportation Research Part A: Policy and Practice, 41(4), pp. 287-301, 2007.

[20] Davis, W.J., Bicycle safety evaluation, Auburn University, 1987.

[21] FDOT, Quality/Level of Service Handbook, Florida Department of Transportation (www.dot.state.fl.us), Online. www.dot.state.fl.us/planning/systems/sm/los/. 2009.

[22] Epperson, B., Evaluating suitability of roadways for bicycle use: Toward a cycling level-of-service standard. In Transportation Research Record 1438, TRB, National Research Council Board, Washington, DC, 1994

[23] Davis, W.J., Bicycle test route evaluation for urban road conditions. Paper presented at the Transportation Congress, 1\&2, sCivil Engineers-Key to the World's Infrastructure, 1995.

[24] Sorton, A. \& Walsh, T., Bicycle stress level as a tool to evaluate urban and suburban bicycle compatibility. Transportation Research Record, TRB, National Research Council, Washington, DC, pp. 17-24, 1994.

[25] Harkey, D.L., Reinfurt, D.W. \& Knuiman, M., Development of the bicycle compatibility index. Transportation Research Record: Journal of the Transportation Research Board, 1636(1), pp. 13-20, 1998

[26] Hallett, I., Luskin, D. \& Machemehl, R., Evaluation of On-Street Bicycle Facilities Added to Existing Roadways (no. FHWA/TXDOT-06/0-5157-1). Austin: Center for Transportation Research, The University of Texas at Austin, 2007.

[27] Landis, B.W., Bicycle interaction hazard score: a theoretical model. Transportation Research Record 1438, TRB, National Research Council, Washington, DC, pp. 3-8, 1994.

[28] Landis, B.W., Bicycle System Performance Measures: The Interaction Hazard and Latent Demand Score Models. ITE Journal, 66(2), 1996.

[29] Landis, B.W., Vattikuti, V.R. \& Brannick, M.T., Real-time human perceptions: toward a bicycle level of service. Transportation Research Record: Journal of the Transportation Research Board, 1578(1), pp. 119-126, 1997.

[30] Carter, D.L., Hunter, W.W., Zegeer, C.V., Stewart, J.R. \& Huang, H., Bicyclist intersection safety index. Transportation Research Record, 2031(18), 2007.

[31] Whyte, W.H., City: Rediscovering the Center, University of Pennsylvania Press, 1988.

[32] Jensen, S.U., Pedestrian and Bicyclist Level of Service on Roadway Segments. Transportation Research Record: Journal of the Transportation Research Board, 2031(1), pp. 43-51, 2007.

[33] Hankey, S., Lindsey, G., Wang, X., Borah, J., Hoff, K., Utecht, B. \& Xu, Z., Estimating use of non-motorized infrastructure: Models of bicycle and pedestrian traffic in Minneapolis, MN. Landscape and Urban Planning, 107(3), pp. 307-316, 2012.

[34] Greene, W.H. \& Hensher, D.A., Modelling ordered choices, New York, 2009.

[35] HCM, Highway Capacity Manual, Transportation Research Board, National Research Council, Washington D.C., 2000. 
[36] Landis, B.W., Vattikuti, V.R., Ottenberg, R.M., Petritsch, T.A., Guttenplan, M. \& Crider, L.B., Intersection level of service for the bicycle through movement. Transportation Research Record: Journal of the Transportation Research Board, 1828(1), pp. 101-106, 2003.

[37] Zhang, L. \& Prevedouros, P.D., Signalized intersection level of service incorporating safety risk. Transportation Research Record. Journal of the Transportation Research Board, 1852(1), pp. 77-86, 2003. 